This item was submitted to Loughborough's Research Repository by the author.

Items in Figshare are protected by copyright, with all rights reserved, unless otherwise indicated.

\title{
Exercise trained postmenopausal women have higher arterial stiffness than men before and after an acute bout of dynamic exercise
}

PLEASE CITE THE PUBLISHED VERSION

https://heart.bmj.com/content/104/Suppl_6/A110.2

PUBLISHER

BMJ Publishing Group

VERSION

AM (Accepted Manuscript)

\section{PUBLISHER STATEMENT}

This article has been accepted for publication in Heart, 2018 following peer review, and the Version of Record can be accessed online at https://doi.org/10.1136/heartjnl-2018-BCS.152.

\section{LICENCE}

CC BY-NC-ND 4.0

\section{REPOSITORY RECORD}

Craig, Jen, Emma ODonnell, and Richard Ferguson. 2018. "Exercise Trained Postmenopausal Women Have Higher Arterial Stiffness Than Men Before and After an Acute Bout of Dynamic Exercise”. figshare. https://hdl.handle.net/2134/11931651.v1. 
Title: Exercise trained postmenopausal women have higher arterial stiffness than men before and after an acute bout of dynamic exercise

Key words: Arterial stiffness, exercise, sex differences

Objectives: Arterial stiffness, peripheral wave reflection and pulse pressure predict cardiovascular disease risk. Regular aerobic exercise training is a recommended nonpharmacological approach to lower cardiovascular disease risk, including lowering blood pressure and attenuating age-related increases in arterial stiffness (AS). However, it remains unclear whether sex differences differentially modulate vascular adaptations to exercise training and/or influence vascular compliance. Thus, we sought to examine the independent and combined effects of aerobic conditioning and an acute bout of dynamic exercise, a known nitric oxide stimulus, on AS in healthy middle-aged men and postmenopausal women (PMW).

Methods: Two age-matched (54 \pm 1 years; mean \pm SEM) groups of habitually aerobically trained men ( $\mathrm{n}=6$; $\left.\mathrm{VO}_{2 \text { peak }} 49.8 \pm 1.2 \mathrm{ml} / \mathrm{kg} / \mathrm{min}\right)$ and postmenopausal women $\left(\mathrm{n}=6\right.$; $\mathrm{VO}_{2 \text { peak }}$ $38.5 \pm 1.4 \mathrm{ml} / \mathrm{kg} / \mathrm{min}$ ) were studied. Pulse wave analysis using applanation tonometry methods was used to assess arterial stiffness (augmentation pressure [AP; mmHg] and augmentation index corrected for heart rate [AIx75; \%]). Central measures of blood pressure (systolic BP, SBP; diastolic BP, DBP; pulse pressure, PP; $\mathrm{mmHg}$ ) were determined using a validated transfer function. AS and BP were recorded at baseline and 60 minutes after an acute bout of moderate intensity exercise (45-min of brisk walking at $60 \% \mathrm{VO}_{2}$ peak).

Results: Our preliminary findings (see table 1) demonstrate that baseline AP and Alx75 were higher, $(p<0.05)$ in PMW compared with M. Groups did not differ $(p>0.05)$ for baseline measures of central BP but brachial SBP and PP were lower $(p<0.05)$ in PMW. Within groups, exercise lowered $(p<0.05)$ all measures of brachial and central BP and indices of arterial stiffness in both M and PMW. Between groups, post-exercise Alx75 remained lower $(p<0.05)$ in $M$, and brachial SBP and PP lower in PMW $(p<0.05)$. Within condition, delta (central - peripheral) BP values, and peripheral-to-central PP ratio were higher $(p<0.05)$ in $M$ before and after exercise. Between conditions, delta (pre - post-exercise) central PP and brachial PP were positively correlated $(p<0.05)$ with delta (pre - post-exercise) Alx75 in men only. 
Conclusions: Our preliminary findings suggest that compared with habitually aerobically trained PMW, trained men demonstrate lower peripheral wave reflection yet higher PP amplification both before and after an acute bout of exercise. Associations between PP and Alx75 were observed in men but not women. While the clinical significance of these findings cannot be determined, these observations suggest: i) arterial stiffness is lower in aerobically trained men versus women, and ii) the relationship between PP and arterial stiffness may differ between men and women. Such differences may be of relevance to the known sex differences in the development and progression of hypertension with ageing.

Table 1. Blood pressure and arterial stiffness values at baseline and one-hour post-exercise

\begin{tabular}{|c|c|c|c|c|}
\hline & \multicolumn{2}{|c|}{ PMW (n=6) } & \multicolumn{2}{|c|}{$M(n=6)$} \\
\hline & PreEx & PostEx & PreEx & PostEx \\
\hline HR (beats per minute) & $54.5 \pm 3.0$ & $61.7 \pm 2.0^{\mathrm{a}}$ & $46.8 \pm 2.7$ & $49.8 \pm 2.9^{* *}$ \\
\hline Brachial SBP (mmHg) & $110.8 \pm 4.5$ & $105.3 \pm 2.8^{a}$ & $128.8 \pm 2.2^{*}$ & $119.3 \pm 1.8^{* * a}$ \\
\hline Brachial DBP $(\mathrm{mmHg})$ & $71.7 \pm 2.5$ & $68.8 \pm 1.8^{a}$ & $76.5 \pm 2.3$ & $70.3 \pm 1.3^{a}$ \\
\hline Brachial PP (mmHg) & $39.2 \pm 2.7$ & $36.5 \pm 2.8^{a}$ & $52.3 \pm 3.1^{*}$ & $49.0 \pm 1.8^{* * a}$ \\
\hline Central SBP (mmHg) & $107.6 \pm 4.0$ & $98.7 \pm 2.5^{a}$ & $114.1 \pm 2.2$ & $102.8 \pm 2.5^{a}$ \\
\hline Central DBP $(\mathrm{mmHg})$ & $73.0 \pm 2.6$ & $69.8 \pm 1.8^{a}$ & $77.0 \pm 2.2$ & $71.1 \pm 1.3^{a}$ \\
\hline Central PP $(\mathrm{mmHg})$ & $34.6 \pm 2.2$ & $28.8 \pm 2.3^{a}$ & $37.1 \pm 2.3$ & $31.8 \pm 1.6^{a}$ \\
\hline PP Ratio & $1.1 \pm 0.01$ & $1.3 \pm 0.01^{\mathrm{a}}$ & $1.4 \pm 0.07^{*}$ & $1.6 \pm 0.08^{* * a}$ \\
\hline AP $(\mathrm{mmHg})$ & $12.1 \pm 1.1$ & $8.0 \pm 0.9^{a}$ & $5.8 \pm 1.6^{*}$ & $2.2 \pm 1.8^{* \star a}$ \\
\hline Alx75 (\%) & $25.0 \pm 2.7$ & $20.2 \pm 2.1^{a}$ & $1.2 \pm 3.4^{*}$ & $-7.2 \pm 4.1^{* \star a}$ \\
\hline
\end{tabular}

Values are mean \pm SEM

* TrPMW vs. TrM pre-exercise, $p<0.05$

** TrPMW vs. TrM post-exercise, $p<0.05$

a Pre vs. post-exercise within groups, $p<0.05$ 